\title{
Characterization, Phylogenetic Analyses, and Pathogenicity of Enterobacter cloacae on Rice Seedlings in Heilongjiang Province, China
}

\author{
Peng Cao, ${ }^{1}$ Chenxu Li, ${ }^{1}$ Kefei Tan, ${ }^{2}$ Chuanzeng Liu, ${ }^{2}$ Xi Xu, ${ }^{1}$ Shaoyong Zhang, ${ }^{3}$ Xiangjing Wang, ${ }^{1}$ Junwei Zhao,,${ }^{1, \dagger}$ \\ and Wensheng Xiang $1,4, \dagger$ \\ ${ }^{1}$ Key Laboratory of Agricultural Microbiology of Heilongjiang Province, Northeast Agricultural University, 600 Changjiang \\ Road, Xiangfang District, Harbin 150030, P.R. China \\ ${ }^{2}$ Qiqihar Branch of Heilongjiang Academy of Agricultural Sciences, Qiqihar, P.R. China \\ ${ }^{3}$ Key Laboratory of Vector Biology and Pathogen Control of Zhejiang Province, College of Life Science, Huzhou University, \\ Huzhou, P.R. China \\ ${ }^{4}$ State Key Laboratory for Biology of Plant Diseases and Insect Pests, Institute of Plant Protection, Chinese Academy of Agricultural \\ Sciences, Beijing, P.R. China
}

\begin{abstract}
Rice is used as a staple food in different areas of world, especially in China. In recent years, rice seedlings have been affected seriously by symptoms resembling bacterial palea browning (BPB) in Heilongjiang Province. To isolate and identify the pathogenic bacteria responsible for the disease, 40 bacterial strains were isolated from diseased rice seedlings collected from the four major accumulative-temperature zones of rice fields cultivated in Heilongiiang Province, and these were identified as 13 species based on morphological characteristics and $16 \mathrm{~S}$ ribosomal RNA (rRNA) gene sequences. Inoculation of all the isolates on healthy rice seedlings showed that the nine Enterobacter cloacae isolates were

on the seedlings of soybean (Glycine max), maize (Zea mays L.), and tomato (Solanum lycopersicum). Phylogenetic analysis based on the $16 \mathrm{~S}$ rRNA gene sequences and phenotypic and biochemical characteristics indicated that these nine pathogenic isolates were E. cloacae. In addition, analysis of the sequences of four housekeeping genes $(r p o B, g y r B$, inf $B$, and $a t p D$ ) from the selected strain SD4L also assigned the strain to $E$. cloacae. Therefore, E. cloacae is the pathogen causing disease of rice seedlings in Heilongjiang Province, which we propose to classify as a form of BPB. To the best of our knowledge, this is the first study to identify $E$. cloacae as a causal agent of $\mathrm{BPB}$ in rice.
\end{abstract} the pathogens causing typical symptoms of BPB, including yellowing to pale browning, stunting, withering, drying, and death. Moreover, the nine $E$. cloacae isolates could also cause symptoms of bacterial disease
Keywords: 16S rRNA gene, bacterial palea browning, Enterobacter cloacae, rice
Globally, rice (Oryza sativa L.) is considered as a major food crop for people. Over 3.5 billion people rely on rice as their staple food and source of daily calories (Cheng et al. 2007), particularly in Asia; nearly $90 \%$ of the world's rice is produced and consumed in this region (Gumma et al. 2011). Certainly, rice is also one of the most important food crops in China and plays an important role in agricultural energy. Heilongjiang Province is an important rice-planting area in northeast China. The yield and quality of rice in Heilongjiang Province are directly related to national food security but also affect the stability of the economy. Bacterial palea browning (BPB), typically caused by Pantoea agglomerans (Gavini et al. 1983, 1989; Kim et al. 1989; Tabei et al. 1988), P. ananatis (Azegami 2013; Cortesi and Pizzatti 2007), and $P$. ananas (Hasegawa et al. 2003; Mergaert et al. 1993), is a devastating and destructive disease of rice. Infection of plants

${ }^{\dagger}$ Corresponding authors: J. Zhao; guyan2080@126.com;

and W. Xiang; xiangwensheng@neau.edu.cn

Funding: This work was supported, in part, by grants from the National Key Research and Development Program of China (number 2017YFD0201606), the National Natural Youth Science Foundation of China (number 31701858), the China Postdoctoral Science Foundation (2018M631907), the Heilongiiang Postdoctoral Fund (LBH-Z17015), the University Nursing Program for Young Scholars with Creative Talents in Heilongjiang Province (UNPYSCT-2017017), and the Young Talents Project of Northeast Agricultural University (17QC14).

The author(s) declare no conflict of interest.

Accepted for publication 4 February 2020.

(C) 2020 The American Phytopathological Society by the BPB at the heading and flowering stages results in quality reduction, while infection at early stages causes severe damage (Azegami 2013; González et al. 2015; Hasegawa et al. 2003; Kim et al. 1989; Lee et al. 2010). BPB infection may be noticed at the seedling stage. The symptoms are characterized by yellowing of leaves, which starts from the tips of leaves and proceeds downward, with leaves later turning pale brown and dry in paddy fields (Azegami 2013; González et al. 2015; Hasegawa et al. 2003; Lee et al. 2010; Tabei et al. 1988). The disease is visualized with small droplets of bacterial ooze (pale amber in color) found from the affected portions. The most destructive phase of the disease in the wilt phase resulting from early systemic infection in the nursery or from seed infection (Kim et al. 1989; Tabei et al. 1988).

Enterobacter cloacae is a Gram-negative bacterium most frequently isolated from humans and animals (Doijad et al. 2016; Wu et al. 2018, 2019) and commonly found in the environment (e.g., water and soil) (Kim et al. 1998; Subrahmanyam et al. 2011; Yokozeki et al. 1982). In addition to being a human pathogen (Sanders and Sanders 1997), E. cloacae is also a pathogen of plants, including the plant hosts coconut (George et al. 1976), onion bulb (Schwartz and Otto 2000; Zaid et al. 2011), edible ginger (Nishijima et al. 2004), mulberry (Wang et al. 2008), and papaya fruit (Keith et al. 2008). Plant-growth-promoting E. cloacae strains have been found associated with rice (Shankar et al. 2012) but no Enterobacter rice pathogens have been identified.

In this research, we report on the identification and characterization of the E. cloacae strains isolated from rice seedlings with browning symptoms in Heilongjiang Province, China, and determine their pathogenic responses on rice and other hosts. Due to similarity in phylogeny and symptoms to the disease caused by Pantoea spp., we propose to classify the E. cloacae disease as BPB. This pathogen may present a threat to the production of rice in this area. Identifying 
the causative agent of this disease is necessary to help researchers develop viable disease control strategies. This is the first report of $E$. cloacae causing BPB on rice seedlings.

\section{Materials and Methods}

Sample collection and isolation. Leaves with symptoms from each of 10 randomly selected rice seedlings of each region were cut into pieces of 5 to $10 \mathrm{~mm}$ in length and surface sterilized $(75 \%$ ethanol for $30 \mathrm{~s}$ and $1 \%$ sodium hypochlorite [ $\mathrm{NaClO}$ ] for $3 \mathrm{~min}$ ). After that, samples were macerated in sterilized water and placed on semiselective tryptic soy broth (TSB) (Aoboxing Bio-Tech Co., Ltd., Beijing, China) agar medium and incubated for $48 \mathrm{~h}$ at $28^{\circ} \mathrm{C}$. Single colonies were isolated and restreaked on TSB agar medium at least two consecutive times to purify the strains. Then, the strains were preliminarily identified by morphology and the $16 \mathrm{~S}$ ribosomal RNA (rRNA) gene sequences. The numbers of bacteria were recorded and the percentage of each species was calculated. Stock cultures were stored in sterile distilled water (SDW) in test tubes at $20^{\circ} \mathrm{C}$ or at room temperature. Strains selected for long-term storage were stored in $20 \%$ glycerol at $-80^{\circ} \mathrm{C}$.

Pathogenicity tests. Forty isolates were recovered in this study, and all strains were used for pathogenicity studies on rice seedlings (Table 1). From the 40 isolates, E. cloacae strains that induced $\mathrm{BPB}$ on rice seedlings were also inoculated on the seedlings of soybean (Glycine max), maize (Zea mays L.), and tomato (Solanum lycopersicum) to test their ability to macerate other crops.

All inoculum for this study was prepared from cultures grown on TSB agar medium at $30^{\circ} \mathrm{C}$ for 3 to 5 days. Bacterial suspensions for each strain were prepared by scraping cells from individual cultures into 15 to $20 \mathrm{ml}$ of SDW (Nishijima et al. 2004). These bacterial suspensions were adjusted spectrophotometrically to approximately $10^{8}$ to $10^{9} \mathrm{CFU} / \mathrm{ml}$ with SDW to an optical density at $600 \mathrm{~nm}\left(\mathrm{OD}_{600}\right)$ of 0.5 using a UV spectrophotometer (U-3900; Hitachi Co., Tokyo, Japan) and then immediately misted on the surface of fresh,

Table 1. Rice varieties in different sampling sites and major accumulative temperature zones

\begin{tabular}{lcc}
\hline Variety & \multicolumn{1}{c}{ Sampling site } & $\begin{array}{c}\text { Different } \\
\text { accumulated } \\
\text { temperature zone }\end{array}$ \\
\hline Qijing 10 & Qiqihar city $\left(47^{\circ} 15^{\prime} \mathrm{N}, 123^{\circ} 41^{\prime} \mathrm{E}\right)$ & $\mathrm{I}\left(>2,700^{\circ} \mathrm{C}\right)$ \\
Daohuaxiang 2 & Wuchang city $\left(45^{\circ} 04^{\prime} \mathrm{N}, 127^{\circ} 18^{\prime} \mathrm{E}\right)$ & $\mathrm{II}\left(2,500-2,700^{\circ} \mathrm{C}\right)$ \\
Suijing 18 & $\mathrm{J}^{\prime}$ iansanjiang $\left(47^{\circ} 19^{\prime} \mathrm{N}, 133^{\circ} 26^{\prime} \mathrm{E}\right)$ & $\mathrm{III}\left(2,300-2,500^{\circ} \mathrm{C}\right)$ \\
Longqing 3 & Fuyuan city $\left(48^{\circ} 16^{\prime} \mathrm{N}, 134^{\circ} 34^{\prime} \mathrm{E}\right)$ & $\mathrm{IV}\left(2,100-2,300^{\circ} \mathrm{C}\right)$ \\
\hline
\end{tabular}

Table 2. Amplification and sequencing primers for $\operatorname{gyr} B, \operatorname{rpoB}$, $\operatorname{atp} D$, and $\operatorname{infB}$

\begin{tabular}{ll}
\hline Primers & \multicolumn{1}{c}{ Sequence $\left(\mathbf{5}^{\prime} \mathbf{-} \mathbf{3}^{\prime}\right)$} \\
\hline $\begin{array}{l}\text { Amplification primers } \\
r p o B \text { CM7-F }\end{array}$ & AAC CAG TTC CGC GTT GGC CTG \\
$r p o B$ CM31b-R & CCT GAA CAA CAC GCT CGG A \\
gyrB 01-F & TAA RTT YGA YGA YAA CTC YTA YAA AGT \\
gyrB 02-R & CMC CYT CCA CCA RGT AMA GTT \\
infB 01-F & ATY ATG GGH CAY GTH GAY CA \\
infB 02-R & ACK GAG TAR TAA CGC AGA TCC A \\
atpD 01-F & RTA ATY GGM GCS GTR GTN GAY GT \\
atpD 02-R & TCA TCC GCM GGW ACR TAW AYN GCC TG \\
Sequencing primers & \\
$r p o B$ CM81-F & CAG TTC CGC GTT GGC CTG \\
$r p o B$ CM32b-R & TGA TCA ACG CCA AGC C \\
gyrB 07-F & GTV CGT TTC TGG CCV AG \\
gyrB 08-R & CTT TAC GRC GKG TCA TWT CAC \\
infB 03-F & ACG GBA TGA TYA CST TCC TGG \\
infB 04-R & AGY TTA GAT TTC TGC TGA CG \\
atpD 03-F & TGC TGG AAG TKC AGC ARC AG \\
atpD 04-R & CCM AGY ART GCG GAT ACT TC \\
\hline
\end{tabular}

healthy, and surface-disinfected leaves of the tested crops with a hand-held spray bottle until runoff (Hou et al. 2019). SDW was used as a control.

Inoculation of rice seedlings in greenhouse. Forty isolates were evaluated for their pathogenicity on the rice seedlings (Qijing 10 varieties). The surface of leaves of the rice seedlings was disinfested using $70 \%$ ethanol $(\mathrm{vol} / \mathrm{vol})$ for $30 \mathrm{~s}$, rinsed with SDW, and air dried prior to inoculation. Two hundred pots (approximately 30 rice seedlings per pot) of 28-day-old rice seedlings were inoculated by spraying bacterial suspensions $\left(10^{8} \mathrm{CFU} / \mathrm{ml}\right.$, as determined by viable counts of serial dilutions of the initial suspension at $\mathrm{OD}_{600}=0.5$ ) on the surface of leaves with a handheld spray bottle until runoff and covered with plastic bags for $24 \mathrm{~h}$. The rice seedlings were placed in a humidified chamber ( $>95 \%$ relative humidity) at $28^{\circ} \mathrm{C}$ for $48 \mathrm{~h}$ after inoculation, then kept in a growth chamber at $25^{\circ} \mathrm{C}$ with $12-\mathrm{h}$ day-and-night cycle. Twenty pots of surface-disinfested rice seedlings inoculated with SDW were used as a control. Disease severity was assessed 9 days after inoculation. The experiment was conducted three times.

Inoculation of soybean, maize, and tomato seedlings in greenhouse. Nine E. cloacae isolates that induced BPB on rice seedlings were inoculated on soybean seedlings (Hefeng 25 varieties). Forty-five pots (four soybean seedlings per pot) of 35-day old soybean seedlings were inoculated by spraying bacterial suspensions $\left(10^{8} \mathrm{CFU} / \mathrm{ml}\right)$ on the surface of disinfested leaves $(70 \%$ ethanol $[\mathrm{vol} / \mathrm{vol}]$ for $30 \mathrm{~s}$, rinsed with SDW, and air dried) as described above and covered with plastic bags for $24 \mathrm{~h}$. The soybean seedlings were placed in a humidified chamber ( $>95 \%$ relative humidity) at $28^{\circ} \mathrm{C}$ for $48 \mathrm{~h}$ after inoculation and then kept in a growth chamber at $25^{\circ} \mathrm{C}$ with 12 -h day-and-night cycle. Ten pots of surface-disinfested soybean seedlings that were inoculated with SDW were used as a control. Inoculation tests were also performed on the seedlings of 30-day-old maize (Tiannong 9 varieties, one maize seedling per pot) and 35-day-old tomato (Qiyanaifen varieties, one tomato seedling per pot) as in the method described above. Disease severity was assessed 9 days after inoculation. All the experiments were conducted two times.

Disease severity was rated based on a slightly modified 0-to-4 disease index scale (Liu et al. in press), where $0=$ no symptoms; $1=$ small lesions on the leaf (covering less than $1 / 4$ of the leaf); $2=$ moderate-sized lesions on the leaf (covering about $1 / 4$ to $1 / 2$ of the leaf); $3=$ large lesions on the leaf (covering about $1 / 2$ to $3 / 4$ of the leaf); and $4=$ dead plants, with lesions covering the whole leaf. The percent disease index for BPB was calculated to determine the pathogenicity of the strains as follows: disease index $<50=$ weakly pathogenic, $50 \leq$ disease index $<60=$ moderately pathogenic, and disease index $\geq 60$ = highly pathogenic.

Reisolation of inoculated bacterial strains. The pathogenic bacteria (E. cloacae isolates) were reisolated from symptomatic tissues of inoculated plants (rice, soybean, maize, and tomato) and species identification was performed by the microscopic, morphological, and molecular methods to fulfill Koch's postulates and conducted according to methods described earlier, with some modifications. Leaves with BPB symptoms from all reisolated plants (rice, soybean, maize, and tomato) were cut into pieces of 5 to $10 \mathrm{~mm}$ in length (rice and maize) or around $0.5 \mathrm{~cm}^{2}$ (soybean and tomato) and surface sterilized (75\% ethanol for $30 \mathrm{~s}, 1 \%$ sodium hypochlorite for $3 \mathrm{~min}$, then washed with SDW). After that, disinfested tissues were placed on semiselective TSB agar medium. Isolations from selected plants inoculated with SDW were similarly performed.

Phenotypic and biochemical characterization of $E$. cloacae isolates. The E. cloacae isolates (SD4L, SD5L, SD22L, SD23L, SD24L, SD32L, SD33L, SD39L, and SD40L) were characterized and identified according to "The Laboratory Guide for Identification of Plant Pathogenic Bacteria" (Schaad 1988) and "Association of Enterobacter cloacae with rhizome rot of edible ginger in Hawaii" (Nishijima et al. 2004). Cell morphology was examined by transmission electron microscopy (Hitachi H-7650; Hitachi Co.). On TSB agar, following incubation for $24 \mathrm{~h}$ at $37^{\circ} \mathrm{C}$, colonies were circular ( 1 to $2 \mathrm{~mm}$ in diameter), white, opaque, and elevated, with a regular margin. Growth at different temperatures $\left(0\right.$ to $45^{\circ} \mathrm{C}$, steps 
of $1^{\circ} \mathrm{C}$ below $5^{\circ} \mathrm{C}$, then intervals of $5^{\circ} \mathrm{C}$, and $37^{\circ} \mathrm{C}$ also included) was determined in TSB agar medium after incubation for 7 days. Growth tests for $\mathrm{pH}$ ranging from 4.0 to 12.0 in 1.0-pH unit intervals and $\mathrm{NaCl}$ tolerance ( 0 to $10 \%$ [wt/vol] in $1 \%$ intervals) were determined in TSB medium at $37^{\circ} \mathrm{C}$ for 7 days on a rotary shaker. The buffer systems were $\mathrm{pH} 4.0$ to $5.0,0.1 \mathrm{M}$ citric acid per $0.1 \mathrm{M}$ sodium citrate; $\mathrm{pH} 6.0$ to $8.0,0.1 \mathrm{M} \mathrm{KH}_{2} \mathrm{PO}_{4}$ per $0.1 \mathrm{M} \mathrm{NaOH} ; \mathrm{pH}$ 9.0 to $10.0,0.1 \mathrm{M} \mathrm{NaHCO}_{3}$ per $0.1 \mathrm{M} \mathrm{Na}_{2} \mathrm{CO}_{3}$; and $\mathrm{pH} 11.0$ to 12.0 , $0.2 \mathrm{M} \mathrm{KH}_{2} \mathrm{PO}_{4}$ per $0.1 \mathrm{M} \mathrm{NaOH}$ (Zhao et al. 2019). Growth was determined by monitoring the turbidity at $\mathrm{OD}_{600}$ using a spectroscopic method (U-3900; Hitachi Co.) and plate counting. Basic biochemical characterization of the isolates was achieved using the API 20E kit following the manufacturer's instructions (bioMérieux). Intrastrain variations were further tested using the API$50 \mathrm{CH}$ kit (bioMérieux). Motility tests were performed under the light microscope on cells grown for $24 \mathrm{~h}$ at $37^{\circ} \mathrm{C}$ in nutrient broth. Catalase activity was determined by observing bubble formation after dropping $\mathrm{H}_{2} \mathrm{O}_{2}$ on 24-h-old biomass on nutrient agar. Oxidase activity was tested by using oxidase reagent (bioMérieux). Antibiotic susceptibility testing was performed using the VITEK 2 compact system with AST N117 cards (bioMérieux).

Molecular characterization. DNA extraction. DNA of all the strains isolated from this study was obtained from single colonies that grew for $24 \mathrm{~h}$ in TSB medium at $37^{\circ} \mathrm{C}$, using the TIANamp Bacteria DNA Kit (TIANGEN Biotech, Co. Ltd., Beijing, China) following the manufacturer's instructions.

$16 S$ rDNA sequencing. Universal primers $27 \mathrm{~F}$ and $1492 \mathrm{R}$ (Stackebrandt and Goodfellow 1991) were used to amplify and sequence the 16S rRNA gene from the isolates. PCR was carried out in a final volume of $50 \mu \mathrm{l}$, with $1 \times$ PCR Buffer, $1.5 \mathrm{mM} \mathrm{MgCl}_{2}$, $0.2 \mathrm{mM}$ each dNTP, $0.6 \mu \mathrm{M}$ each oligonucleotide, $1.5 \mathrm{U}$ of Taq polymerase, and $10 \mathrm{ng}$ of template DNA. PCR conditions were initial denaturation at $95^{\circ} \mathrm{C}$ for $5 \mathrm{~min}$; followed by 30 cycles of denaturation at $94^{\circ} \mathrm{C}$ for $50 \mathrm{~s}$, annealing at $57^{\circ} \mathrm{C}$ for $30 \mathrm{~s}$, and extension at $72^{\circ} \mathrm{C}$ for $90 \mathrm{~s}$; and a final extension at $72^{\circ} \mathrm{C}$ for 5 min (Eden et al. 1991). Aliquots of $5 \mu \mathrm{l}$ were analyzed by electrophoresis in $1.5 \%$ (wt/vol) agarose in TBE buffer. Gels were stained with ethidium bromide and visualized in a gel documentation system. The PCR products were purified and sequenced using an Applied Biosystems DNA sequencer (model 3730XL; Applied Biosystems Inc., Foster City, CA, U.S.A.) and software provided by the manufacturer.

Phylogenetic analysis. The 16S rRNA gene sequences were identified via Basic Local Alignment Search Tool (BLAST) matches (https:// blast.ncbi.nlm.nih.gov/Blast.cgi) in the NCBI database. Reference sequences used for phylogenetic analysis were downloaded from the NCBI's GenBank sequence database. The 16S rRNA gene sequences were aligned using the ClustalW algorithm and manually adjusted to allow maximum sequence similarity. The aligned file was analyzed using the criterion of neighbor-joining algorithm of Saitou and Nei (1987) by Molecular Evolutionary Genetics Analysis (MEGA) software, version 7.0 (Kumar et al. 2016). The stability of the topology of the phylogenetic tree was assessed using the bootstrap method with 1,000 repetitions (Felsenstein 1985). A distance matrix was generated using Kimura's two-parameter model (Kimura 1980).

$\mathrm{gyrB}, \mathrm{rpoB}$, infB, and atpD sequencing. To further confirm the taxonomic status of the nine E. cloacae isolates, one representative isolate (SD4L) was randomly selected from the nine strains to sequence the four individual housekeeping genes (DNA gyrase [ $g y r B]$, RNA polymerase $\beta$ subunit $[r p o B]$, translation initiation factor 2 $[$ inf $B]$, and, ATP synthase $\beta$ subunit $[a t p D]$ ) using the primers as shown in Table 2 and conditions as described by Brady et al. (2013). PCR and sequencing setup and purification steps were carried out at the Comate Biosciences Co., Ltd., China. Sequences were identified via BLAST matches (https://blast.ncbi.nlm.nih.gov/ Blast.cgi) in the NCBI database. Consensus sequences obtained in this research were all deposited in GenBank.

\section{Results}

Isolation and identification of pathogenic bacteria. In April to May 2018 and 2019, during field trips to different fields of
Heilongjiang Province, it was observed that rice seedlings showed areas of yellow leaves, drying, and death (Fig. 1). Due to the characteristics of these symptoms, it was hypothesized that the diseased rice seedlings could have bacterial leaf blight caused by Xanthomonas oryzae or BPB caused by Pantoea spp. The symptomatic rice seedlings were collected from the four major accumulative-temperature zones

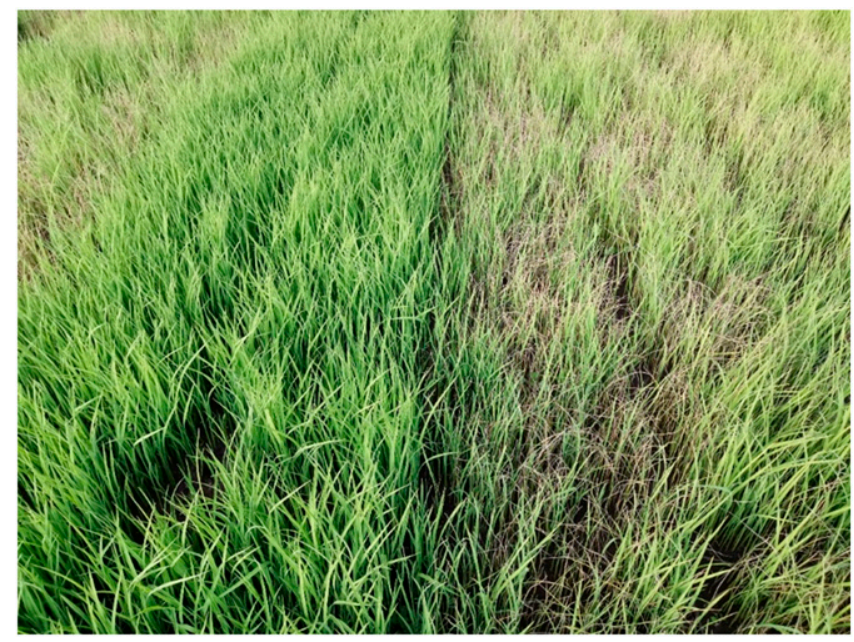

Fig. 1. Symptoms observed on rice seedlings in Heilongjiang Province, China, in 2018.

Table 3. Bacterial species and their frequencies identified from rice bacterial palea browning samples from Heilongjiang Province, China

\begin{tabular}{lcc}
\hline Species & Number of isolates & Frequency $(\boldsymbol{\%})$ \\
\hline Stenotrophomonas maltophilia & 2 & 5.0 \\
Kosakonia cowanii & 3 & 7.5 \\
Enterobacter roggenkampii & 4 & 10.0 \\
S. pavanii & 5 & 12.5 \\
Bacillus altitudinis & 2 & 5.0 \\
Klebsiella oxytoca & 2 & 5.0 \\
K. pneumoniae & 2 & 5.0 \\
Leclercia adecarboxylata & 3 & 7.5 \\
Achromobacter spanius & 2 & 5.0 \\
B. safensis & 3 & 7.5 \\
Paenibacillus polymyxa & 2 & 5.0 \\
Pantoea dispersa & 1 & 2.5 \\
E. cloacae & 9 & 22.5 \\
\hline
\end{tabular}

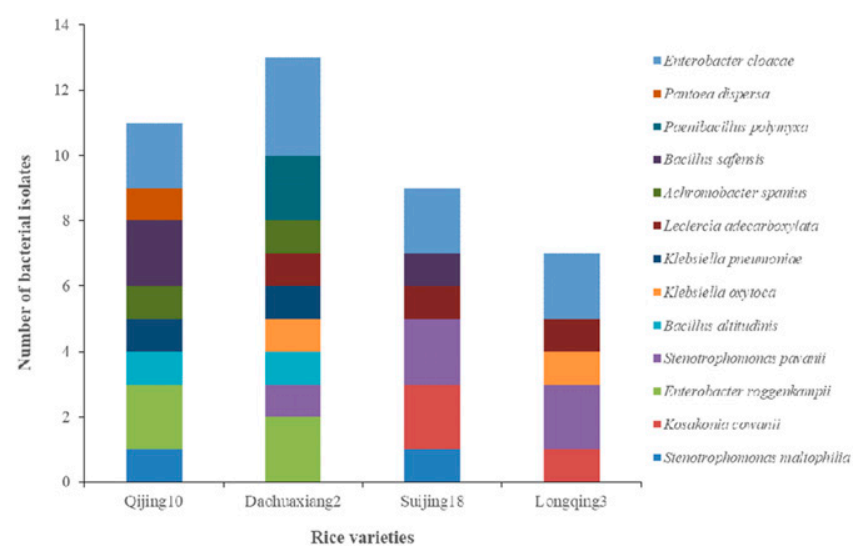

Fig. 2. Bacterial distribution among the four different rice varieties collected from Heilongjiang Province. 
(I, $>2,700^{\circ} \mathrm{C}$; II, 2,500 to $2,700^{\circ} \mathrm{C}$; III, 2,300 to $2,500^{\circ} \mathrm{C}$; and IV, 2,100 to $2,300^{\circ} \mathrm{C}$ ) of Heilongjiang Province to isolate the pathogenic bacteria. In total, 40 bacterial strains were isolated. Based on the high similarity of morphology and 16S rRNA gene sequence (99 to $100 \%$ ), these isolates were identified as the following 13 species (Table 3): 9 E. cloacae isolates (22.5\%), 5 Stenotrophomonas pavanii isolates (12.5\%), 4 E. roggenkampii isolates (10.0\%), 3 Kosakonia cowanii isolates (7.5\%), 3 Leclercia adecarboxylata isolates (7.5\%), 3 Bacillus safensis isolates (7.5\%), 2 S. maltophilia isolates (5.0\%), 2 B. altitudinis isolates (5.0\%), 2 Klebsiella oxytoca isolates (5.0\%), $2 \mathrm{~K}$. pneumonia isolates (5.0\%), 2 Achromobacter spanius isolates (5.0\%), 2 Paenibacillus polymyxa isolates (5.0\%), and 1
Pantoea dispersa isolate (2.5\%). Among the 40 bacterial strains, 11 isolates ( 8 bacterial species) were isolated from rice seedlings of Qijing 10, 13 isolates (9 bacterial species) were isolated from rice seedlings of Daohuxiang 2, 9 isolates (6 bacterial species) were isolated from rice seedlings of Suijing 18, and 7 isolates ( 5 bacterial species) were isolated from rice seedlings of Longqing 3 (Fig. 2). Thus, E. cloacae was identified as the dominant bacterium, which was isolated from all four rice varieties surveyed in the current study.

Symptoms and pathogenicity. Pathogenicity tests on rice seedlings. Pathogenicity tests showed that E. cloacae was the most aggressive species. S. maltophilia, E. roggenkampii, K. pneumonia, A. spanius, B. safensis, S. pavanii, K. oxytoca, L. adecarboxylata,

Table 4. Pathogenicity and geographical location of bacteria isolates from rice in Heilongjiang Province

\begin{tabular}{|c|c|c|c|c|}
\hline Group, number & Isolate & Accession number & Pathogenicity ${ }^{a}$ & Region \\
\hline \multicolumn{5}{|c|}{$\overline{\text { Enterobacter cloacae }}$} \\
\hline 1 & SD4L & MN647552 & $\mathrm{P}(\mathrm{S})$ & Qiqihar \\
\hline 2 & SD5L & MN647553 & $\mathrm{P}(\mathrm{S})$ & Qiqihar \\
\hline 3 & SD22L & MN647556 & $P(S)$ & Wuchang \\
\hline 4 & SD23L & MN647665 & $\mathrm{P}(\mathrm{S})$ & Wuchang \\
\hline 5 & SD24L & MN647741 & $\mathrm{P}(\mathrm{S})$ & Wuchang \\
\hline 6 & SD32L & MN647739 & $\mathrm{P}(\mathrm{S})$ & Jiansanjiang \\
\hline 7 & SD33L & MN647667 & $\mathrm{P}(\mathrm{S})$ & Jiansanjiang \\
\hline 8 & SD39L & MN647736 & $\mathrm{P}(\mathrm{S})$ & Fuyuan \\
\hline 9 & SD40L & MN647742 & $\mathrm{P}(\mathrm{S})$ & Fuyuan \\
\hline \multicolumn{5}{|c|}{ Leclercia adecarboxylata } \\
\hline 10 & SD18L & MN647952 & $\mathrm{N}(\mathrm{W})$ & Wuchang \\
\hline 11 & SD30L & MN649211 & $\mathrm{N}(\mathrm{W})$ & Jiansanjiang \\
\hline 12 & SD38L & MN649212 & $\mathrm{N}(\mathrm{W})$ & Fuyuan \\
\hline \multicolumn{5}{|l|}{ E. roggenkampii } \\
\hline 13 & SD2L & MN647546 & $\mathrm{N}(\mathrm{W})$ & Qiqihar \\
\hline 14 & SD3L & MN647555 & $\mathrm{N}(\mathrm{W})$ & Qiqihar \\
\hline 15 & SD12L & MN647547 & $\mathrm{N}(\mathrm{W})$ & Wuchang \\
\hline 16 & SD13L & MN647554 & $\mathrm{N}(\mathrm{W})$ & Wuchang \\
\hline \multicolumn{5}{|l|}{ Klebsiella oxytoca } \\
\hline 17 & SD16L & MN647786 & $\mathrm{N}(\mathrm{W})$ & Wuchang \\
\hline 18 & SD37L & MN647924 & $\mathrm{N}(\mathrm{W})$ & Fuyuan \\
\hline \multicolumn{5}{|l|}{ K. pneumonia } \\
\hline 19 & SD7L & MN647735 & $\mathrm{N}(\mathrm{W})$ & Qiqihar \\
\hline 20 & SD17L & MN647588 & $\mathrm{N}(\mathrm{W})$ & Wuchang \\
\hline \multicolumn{5}{|c|}{ Kosakonia cowanii } \\
\hline 21 & SD26L & MN648220 & $\mathrm{N}(-)$ & Jiansanjiang \\
\hline 22 & SD27L & MN648221 & $\mathrm{N}(-)$ & Jiansanjiang \\
\hline 23 & SD34L & MN648222 & $\mathrm{N}(-)$ & Fuyuan \\
\hline \multicolumn{5}{|l|}{ Pantoea dispersa } \\
\hline 24 & SD11L & MN647743 & $\mathrm{N}(-)$ & Qiqihar \\
\hline \multicolumn{5}{|c|}{ Achromobacter spanius } \\
\hline 25 & SD8L & MN647606 & $\mathrm{N}(\mathrm{W})$ & Qiqihar \\
\hline 26 & SD19L & MN647627 & $\mathrm{N}(\mathrm{W})$ & Wuchang \\
\hline \multicolumn{5}{|c|}{ Stenotrophomonas maltophilia } \\
\hline 27 & SD1L & MN647536 & $\mathrm{N}(\mathrm{W})$ & Qiqihar \\
\hline 28 & $\mathrm{SD} 25 \mathrm{~L}$ & MN647557 & $\mathrm{N}(\mathrm{W})$ & Jiansanjiang \\
\hline \multicolumn{5}{|l|}{ S. pavanii } \\
\hline 29 & SD14L & MN647752 & $\mathrm{N}(\mathrm{W})$ & Wuchang \\
\hline 30 & SD28L & MN647761 & $\mathrm{N}(\mathrm{W})$ & Jiansanjiang \\
\hline 31 & SD29L & MN647765 & $\mathrm{N}(\mathrm{W})$ & Jiansanjiang \\
\hline 32 & SD35L & MN647766 & $\mathrm{N}(\mathrm{W})$ & Fuyuan \\
\hline 33 & SD36L & MN647784 & $\mathrm{N}(\mathrm{W})$ & Fuyuan \\
\hline \multicolumn{5}{|c|}{ Paenibacillus polymyxa } \\
\hline 34 & SD20L & MN648192 & $\mathrm{N}(\mathrm{W})$ & Wuchang \\
\hline 35 & SD21L & MN649214 & $\mathrm{N}(\mathrm{W})$ & Wuchang \\
\hline \multicolumn{5}{|l|}{ Bacillus altitudinis } \\
\hline 36 & SD6L & MN647559 & $\mathrm{N}(-)$ & Qiqihar \\
\hline 37 & SD15L & MN647666 & $\mathrm{N}(-)$ & Wuchang \\
\hline \multicolumn{5}{|l|}{ B. safensis } \\
\hline 38 & SD9L & MN647651 & $\mathrm{N}(\mathrm{W})$ & Qiqihar \\
\hline 39 & SD10L & MN647738 & $\mathrm{N}(\mathrm{W})$ & Qiqihar \\
\hline 40 & SD31L & MN647740 & $\mathrm{N}(\mathrm{W})$ & Jiansanjiang \\
\hline
\end{tabular}

a Pathogenicity of the strains: pathogenic $(\mathrm{P})$ or not pathogenic $(\mathrm{N})$, disease index $<50$ indicates weak pathogenicity $(\mathrm{W}), 50 \leq$ disease index $<60$ indicates moderate pathogenicity $(\mathrm{M})$, and $60 \leq$ disease index indicates strong pathogenicity $(\mathrm{S})$. 
and Paenibacillus polymyxa did not cause a clear disease response, while Kosakonia cowanii, Pantoea dispersa, and B. altitudinis could not infect rice seedlings (Table 4). Nine days after inoculation, the plants inoculated with E. cloacae developed typical symptoms of yellowing to pale browning, stunting, withering, drying, and death (Fig. 3, only showing inoculation with E. cloacae SD4L), which were similar to those which occur under natural conditions in the rice field in Heilongjiang Province, China (Fig. 1), whereas other weak pathogenic strains did not show the typical symptoms (data not shown). Control samples were free of symptoms (Fig. 3). The E. cloacae isolates were the pathogens causing BPB in the four different accumulated-temperature zones of cultivated rice fields (representing four rice varieties) located in Heilongjiang Province, northeastern China. The inoculated E. cloacae bacteria were successfully reisolated from the inoculated rice seedlings.

To test the ability to macerate other crops, E. cloacae isolates were also inoculated on the seedlings of soybean ( $G$. max), maize (Z. mays L.), and tomato (Solanum lycopersicum).

Pathogenicity tests on soybean, maize, and tomato seedlings. The E. cloacae isolates showed moderate, strong, and moderate pathogenicity on soybean, maize, and tomato seedlings, respectively (Table 5). Nine days after inoculation, symptoms caused by E. cloacae included yellow leaves, stunting, and withered leaves on soybean seedlings; withered leaves, stunting, and death on maize seedlings; and yellow and withered leaves and stunting on tomato seedlings (Fig. 4A to C, only showing inoculation with E. cloacae SD4L). None of the SDW controls showed disease symptoms and the

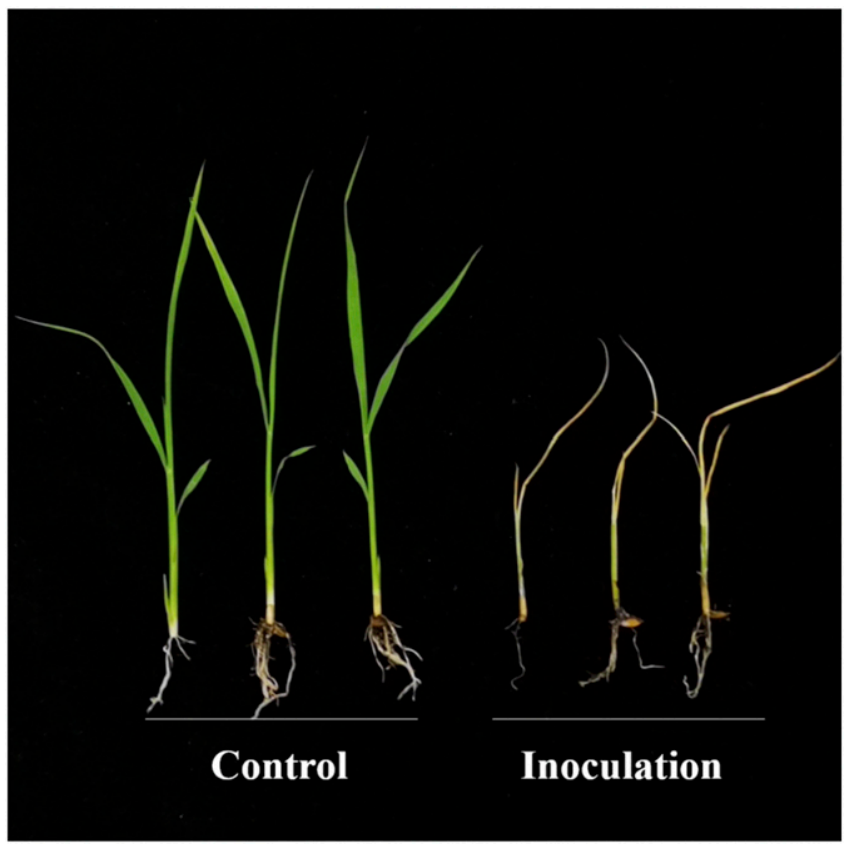

Fig. 3. Symptoms caused by Enterobacter cloacae on the rice seedlings 9 days after inoculation.

Table 5. Pathogenicity on other crops of the Enterobacter cloacae isolates from diseased rice in Heilongjiang Province ${ }^{\mathrm{a}}$

\begin{tabular}{lccc}
\hline Isolates & Soybean & Maize & Tomato \\
\hline SD4L & $\mathrm{M}$ & $\mathrm{S}$ & $\mathrm{M}$ \\
SD5L & $\mathrm{M}$ & $\mathrm{S}$ & $\mathrm{M}$ \\
SD22L & $\mathrm{M}$ & $\mathrm{S}$ & $\mathrm{M}$ \\
SD23L & $\mathrm{M}$ & $\mathrm{S}$ & $\mathrm{M}$ \\
SD24L & $\mathrm{M}$ & $\mathrm{S}$ & $\mathrm{M}$ \\
SD32L & $\mathrm{M}$ & $\mathrm{S}$ & $\mathrm{M}$ \\
SD33L & $\mathrm{M}$ & $\mathrm{S}$ & $\mathrm{M}$ \\
SD39L & $\mathrm{M}$ & $\mathrm{S}$ & $\mathrm{M}$ \\
SD40L & $\mathrm{M}$ & $\mathrm{S}$ & $\mathrm{M}$ \\
\hline
\end{tabular}

\footnotetext{
${ }^{a} \mathrm{M}$ indicates moderate pathogenicity and $\mathrm{S}$ indicates strong pathogenicity.
}

inoculated E. cloacae bacteria were all successfully reisolated from the inoculated soybean, maize, and tomato seedlings.

Phenotypic and biochemical characterization. The nine E. cloacae isolates are Gram-negative, motile, nonspore forming, and facultatively anaerobic. Colonies are circular, white, translucent, raised, and smooth after $24 \mathrm{~h}$ of incubation at $37^{\circ} \mathrm{C}$ on TSB agar. Cells are motile rods ( 0.4 to $0.8 \mu \mathrm{m}$ in width and 0.8 to $1.9 \mu \mathrm{m}$ in length) with peritrichous flagella (Fig. 5). Growth occurs at 4 to $40^{\circ} \mathrm{C}$, with optimal growth at 35 to $37^{\circ} \mathrm{C}$. Growth occurs between pH 5.0 and 10.0 and optimal $\mathrm{pH}$ is 6.0 to 7.0 . Cells grow at $37^{\circ} \mathrm{C}$ in the presence of 0 to $7 \%(\mathrm{wt} / \mathrm{vol}) \mathrm{NaCl}$ in TSB medium. Acid is produced from
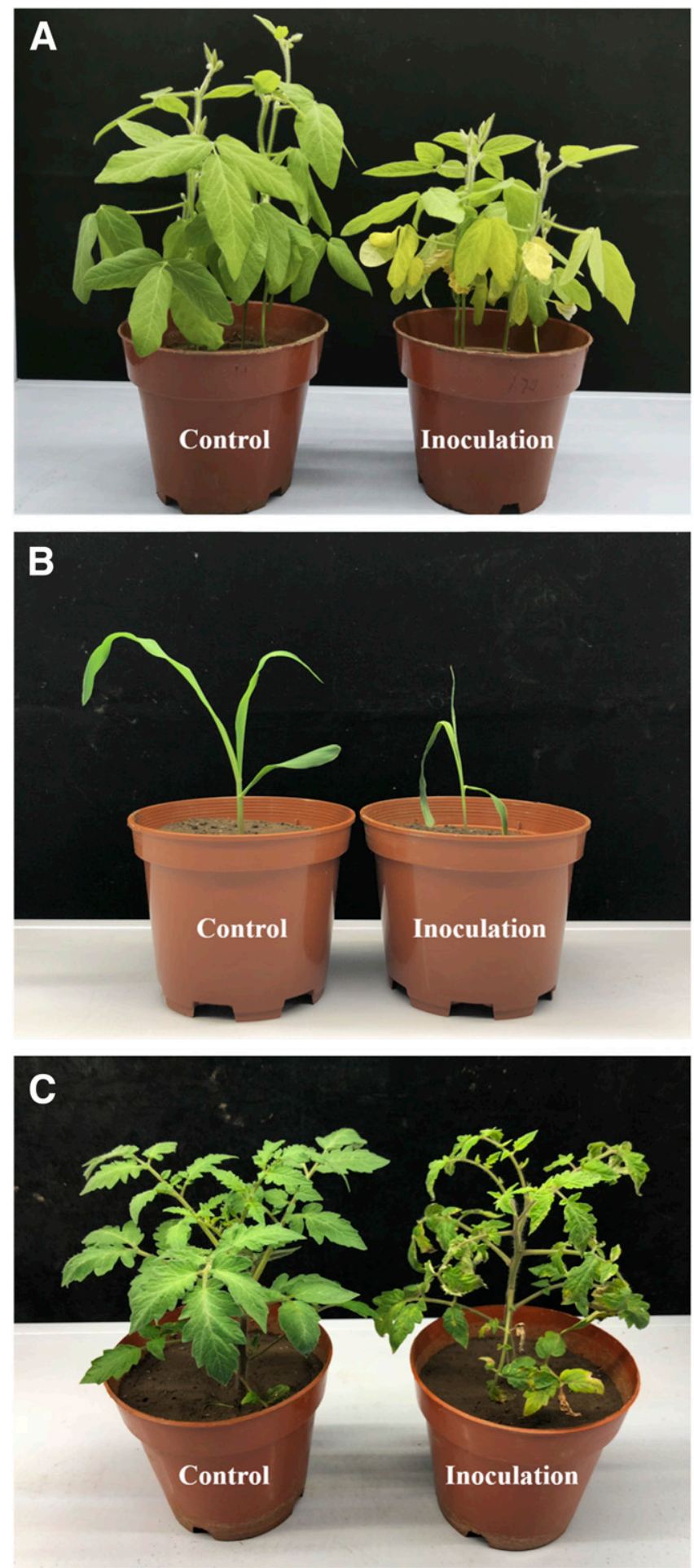

Fig. 4. Symptoms observed 9 days after inoculation on A, soybean (Glycine max); $\mathbf{B}$, maize (Zea mays L.); and C, tomato (Solanum lycopersicum). 
arbutin, D-adonitol, cellobiose, D-fructose, D-galactose, Dglucose, maltose, D-mannitol, raffinose, D-ribose, D-sorbitol, trehalose, D-xylose, aesculin, gentiobiose, glycerol, melibiose, Larabinose, L-rhamnose, salicin, and sucrose but not from lactose,

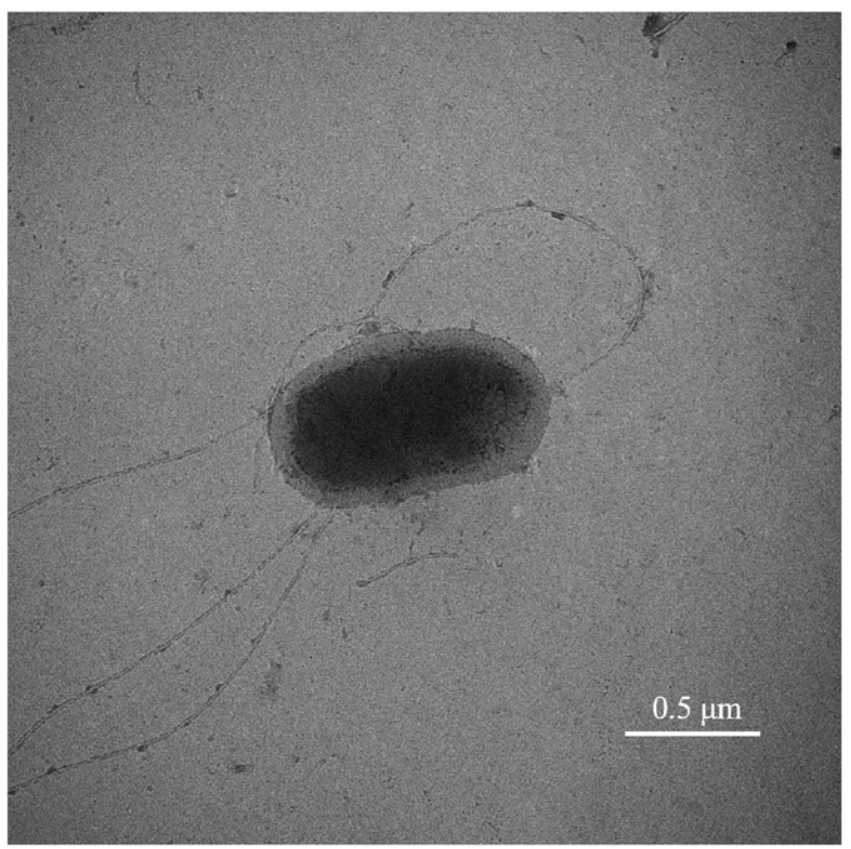

Fig. 5. Transmission electron microscopy of Enterobacter cloacae on tryptic soy broth agar after incubation for $24 \mathrm{~h}$ at $37^{\circ} \mathrm{C}$. Bar $=0.5 \mu \mathrm{m}$.
D-mannose, methyl $\alpha$-D-glucopyranoside, N-acetylglucosamine, amygdalin, starch, dulcitol, D-arabinose, melezitose, D-lyxose, erythritol, glucogen, inositol, inulin, L-sorbose, L-xylose, methyl $\alpha$-D-mannopyranoside, methyl $\beta$-D-xylopyranoside, potassium 5-ketogluconate potassium gluconate, or xylitol. All isolates have positive reactions for arginine dihydrolase, $\beta$-galactosidase, and ornithine decarboxylase but are negative for lysine decarboxylase, deaminase, and gelatinase. They are also negative for urease activity and indole production but are positive for the Voges-Proskauer reaction. They can utilize lactose but not produce $\mathrm{H}_{2} \mathrm{~S}$. They are catalase positive and oxidase negative. They can produce pectate lyase, polygalacturonase, cellulase, and proteases. Almost all of the biochemical and physiological characters were matched with E. cloacae as described by Richard (1984), except for a negative reaction for production of gelatinase (Table 6). All nine E. cloacae isolates were resistant to ampicillin, cefazolin, cefotetan, cefuroxime, and cephalothin and susceptible to amikacin, gentamicin, tobramycin, aztreonam, cefepime, cefotaxime, cefpodoxime, ceftazidime, ceftizoxime, ceftriaxone, doripenem, ertapenem, imipenem, meropenem, piperacillin, ticarcillin, ciprofloxacin, levofloxacin, moxifloxacin, nalidixic acid, norfloxacin, tetracycline, and tigecycline. These results demonstrated that the nine isolates should be E. cloacae.

Molecular characterization. Phylogenetic analysis. The GenBank accession numbers for the 16S rRNA gene sequences from each strain are listed in Table 4. In total, 53 strains (including 40 isolates in this study and 13 typical reference strains) were used to construct the phylogenetic tree based on the 16S rRNA gene sequences (Fig. 6). The phylogenetic analysis clustered the 40 isolates into the following 12 main clades: E. cloacae clade contained 9 isolates (SD4L, SD5L, SD22L, SD23L, SD24L, SD32L, SD33L, SD39L, and SD40L); L. adecarboxylata clade

Table 6. Biochemical and physiological characteristics of Enterobacter cloacae $(E c)$ in this study and the nine type strains of E. cloacae

\begin{tabular}{|c|c|c|c|c|c|c|c|c|c|c|}
\hline \multirow[b]{2}{*}{ Characteristics } & \multirow[b]{2}{*}{$E c^{\mathbf{b}}$} & \multicolumn{9}{|c|}{ Strains } \\
\hline & & SD4L & SD5L & SD22L & SD23L & SD24L & SD32L & SD33L & SD39L & $\overline{\text { SD40L }}$ \\
\hline$\beta$-Galactosidase & + & + & + & + & + & + & + & + & + & + \\
\hline Arginine dihydrolase & + & + & + & + & + & + & + & + & + & + \\
\hline Lysine decarboxylase & - & - & - & - & - & - & - & - & - & - \\
\hline Ornithine decarboxylase & + & + & + & + & + & + & + & + & + & + \\
\hline Citrate utilization & + & + & + & + & + & + & + & + & + & + \\
\hline $\mathrm{H}_{2} \mathrm{~S}$ production & - & - & - & - & - & - & - & - & - & - \\
\hline Urease hydrolysis & - & - & - & - & - & - & - & - & - & - \\
\hline Deaminase & - & - & - & - & - & - & - & - & - & - \\
\hline Indole production & - & - & - & - & - & - & - & - & - & - \\
\hline Voges-Proskauer reaction & + & + & + & + & + & + & + & + & + & + \\
\hline Gelatinase & + & - & - & - & - & - & - & - & - & - \\
\hline D-Glucose & + & + & + & + & + & + & + & + & + & + \\
\hline M-Mannitol & + & + & + & + & + & + & + & + & + & + \\
\hline Inositol & - & - & - & - & - & - & - & - & - & - \\
\hline D-Sorbitol & + & + & + & + & + & + & + & + & + & + \\
\hline L-Rhamnose & + & + & + & + & + & + & + & + & + & + \\
\hline Sucrose & + & + & + & + & + & + & + & + & + & + \\
\hline Melibiose & + & + & + & + & + & + & + & + & + & + \\
\hline Amygdalin & + & + & + & + & + & + & + & + & + & + \\
\hline Arabinose & + & + & + & + & + & + & + & + & + & + \\
\hline Oxidase & - & - & - & - & - & - & - & - & - & - \\
\hline Nitrate reduction & + & + & + & + & + & + & + & + & + & + \\
\hline Catalase & + & + & + & + & + & + & + & W & + & + \\
\hline \multicolumn{11}{|l|}{ Other tests } \\
\hline Anaerobic growth & + & + & + & + & + & + & + & + & + & + \\
\hline Phenylalanine deaminase & - & - & - & - & - & - & - & - & - & - \\
\hline Pectate degradation & - & - & - & - & - & - & - & - & - & - \\
\hline Motility & + & + & + & + & + & + & + & + & + & + \\
\hline \multicolumn{11}{|l|}{ Acid from } \\
\hline Cellobiose & + & + & + & + & + & + & + & + & + & + \\
\hline Lactose & + & + & + & + & + & + & + & + & + & + \\
\hline$\alpha$-Methyl-D-glucoside & + & + & + & + & + & + & + & + & + & + \\
\hline
\end{tabular}

a Symbols: + indicates positive reactions, - indicates negative reactions, and $\mathrm{W}$ indicates weak reactions.

b Data from Richard (1984). 
contained 3 isolates (SD18L, SD30L, and SD38L); E. roggenkampii clade contained 4 isolates (SD2L, SD3L, SD12L, and SD13L); Klebsiella oxytoca clade contained 2 isolates (SD16L and SD37L); K. pneumonia clade contained 2 isolates (SD7L and SD17L); Kosakonia cowanii clade contained 3 isolates (SD26L, SD27L, and SD34L); P. dispersa clade contained 1 isolate (SD11L); A. spanius clade contained 2 isolates (SD8L and SD19L); Stenotrophomonas maltophilia and $S$. pavanii clade contained 7 isolates (SD1L, SD14L, SD25L, SD28L, SD29L, SD35L, and SD36L); Paenibacillus polymyxa clade contained 2 isolates (SD20L and SD21L); B. altitudinis clade contained 2 isolates (SD6L and SD15L); and B. safensis clade contained 3 isolates (SD9L, SD10L, and SD31L). gyrB, rpoB, infB, and atpD sequencing. The resulting nucleotide sequences lengths of isolate SD4L were $\operatorname{gyr} B=742 \mathrm{bp}, r p o B=$ $637 \mathrm{bp}, \operatorname{atp} D=642 \mathrm{bp}$, and $\inf B=615 \mathrm{bp}$. Partial sequences of the four housekeeping genes of $\operatorname{gyr} B, \operatorname{rpoB}, \operatorname{atpD}$, and $\inf B$ of the strain have been deposited in GenBank under accession numbers MN325087 to MN325090. BLAST analysis revealed that these four housekeeping gene sequences of isolate SD4L were 97.9, 99.5, 99.6, and 97.9\%, respectively, similar to those of E. cloacae strain colR/S (CP010512). This result also confirmed that SD4L belongs to E. cloacae.

Based on pathogenicity and phenotypic and molecular characterization, the causal agent of BPB that affects rice seedling in Heilongjiang Province, China is E. cloacae.

\section{Discussion}

Rice BPB has been responsible for severe decreases in quality in many countries. Previous studies have shown that BPB was mainly caused by Pantoea agglomerans (Gavini et al. 1983, 1989; Kim et al. 1989; Tabei et al. 1988), P. ananatis (Azegami 2013; Cortesi and Pizzatti 2007), and P. ananas (Hasegawa et al. 2003; Mergaert et al. 1993). In this study, 13 species were isolated from diseased rice seedlings collected from the four major accumulative-temperature zones of cultivated rice fields of Heilongjiang Province in 2018-2019

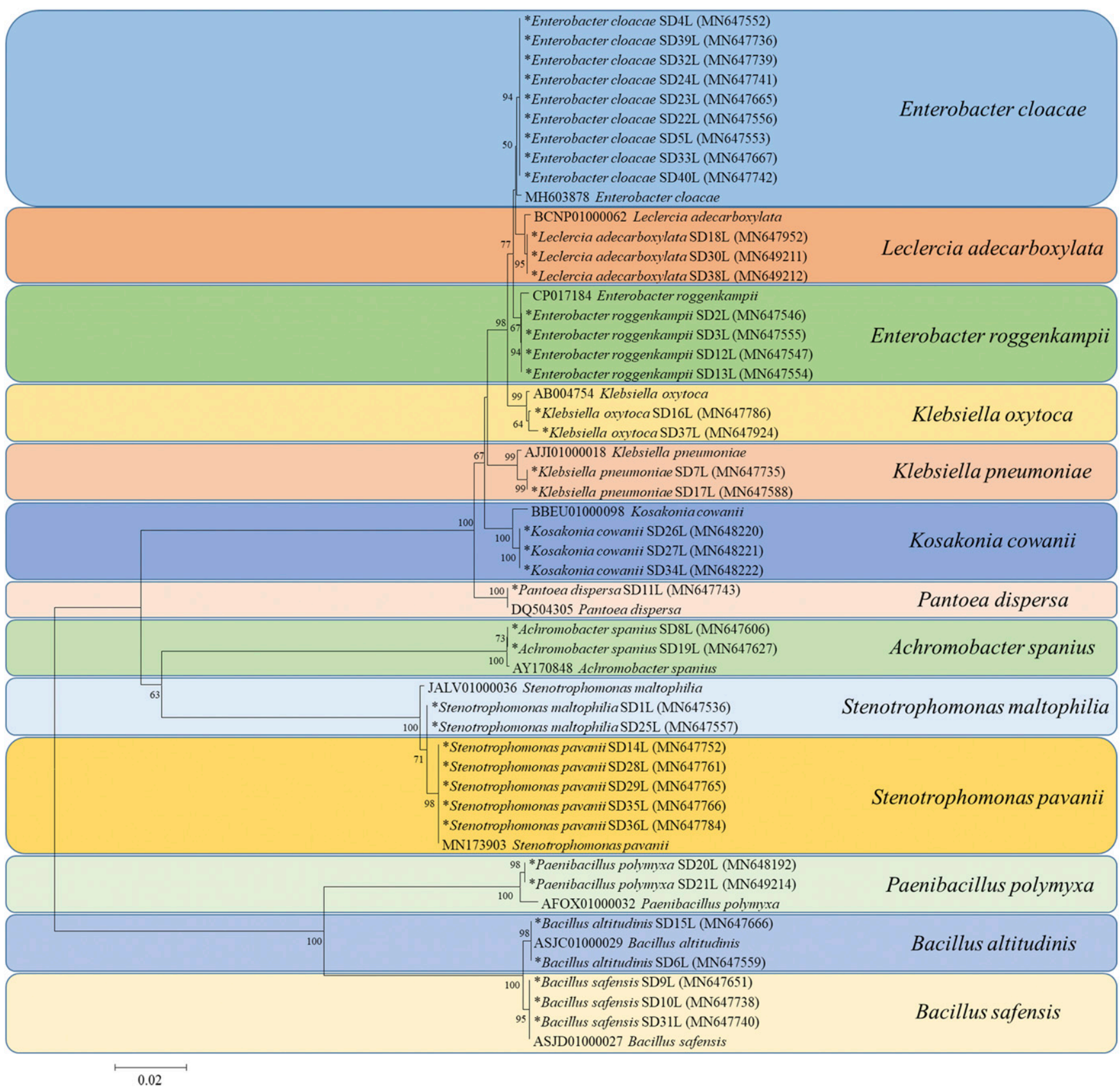

Fig. 6. Phylogenetic tree based on the 16S ribosomal RNA gene sequences constructed using the neighbor-joining method of the MEGA7. Bacterial strains analyzed in the current study are shown with their organism name, isolate code, and accession number in parentheses. Sequences derived from the NCBI are shown with their accession number and organism name. Bootstrap values (1,000 replicates) above $50 \%$ are shown at the nodes, and the scale bar indicates 2 changes per 100 nucleotide positions. 
(Table 3; Fig. 2). However, none of the species were previously associated with rice disease in China. Of these 13 species, E. cloacae has been reported as a pathogen of coconut (George et al. 1976), onion bulb (Schwartz and Otto 2000; Zaid et al. 2011), edible ginger (Nishijima et al. 2004), mulberry (Wang et al. 2008), and papaya fruit (Keith et al. 2008); Klebsiella pneumonia has been reported as a pathogen causing bulb disease on onion in China (Liu et al. 2015). P. dispersa was recorded on rice in Malaysia as a leaf blight pathogen (Toh et al. 2019) but our studies showed that it was not pathogenic to rice seedlings. Paenibacillus polymyxa has been reported as a causal agent of bacterial stem rot on Hylocereus undulates in China (Zhang et al. 2017). In this research, E. cloacae isolates $(n=9,22.5 \%)$ were isolated from all four rice varieties (Table 4 ) and were identified as the pathogen. The pathogen E. cloacae caused typical symptoms of browning, stunting, withering, and death of rice seedlings (Fig. 3 ), which started from the tips of leaves and proceeded downward. These results are similar to the symptoms of BPB (Kim et al. 1989; Tabei et al. 1988). Therefore, we hypothesize that E. cloacae invades the plant through hydathodes at the leaf tip and leaf margin; then, the lesions enlarge in size, turn yellow to pale brown and dry, and ultimately lead to death of the plant, similar to the infection process of Pantoea disease (Tabei et al. 1988). Interestingly, although Pantoea agglomerans, $P$. ananatis, and $P$. ananas have been reported as pathogens causing BPB on rice, the three species were not recovered from the diseased rice seedling samples surveyed in the present research, and there were also no related reports in Heilongjiang Province in previous studies. Moreover, E. cloacae was also inoculated on soybean, maize, and tomato seedlings and could induce the symptoms of withered leaves, stunting, drying or yellowing, or death. These results indicated that this strain of E. cloacae has a broad host range.

The pathogenicity of E. cloacae isolates is perhaps based on the ability to produce a range of enzymes such as pectate lyase, polygalacturonase, cellulase, and proteases that degrade structural components of the cell wall and infect the host (Lee et al. 2014; Toth and Birch 2005). In addition, mucoid colonies of the E. cloacae isolates were observed on TSB agar medium. The importance of mucoid forms of E. cloacae has been reported by Nishijima et al. (2004), although extracellular polysaccharide production may provide the bacteria with some protection in harsh environments (Meade et al. 1993) or may be a factor in causing disease symptoms in plant hosts. The main goal of this research was to identify the causal agent of BPB. Future studies should focus on the genetic variability and virulence and aggressiveness of the E. cloacae isolates.

To the best of our knowledge, this is the first report of E. cloacae as a rice seedling pathogen in China. It is unknown whether $E$. cloacae has coevolved with rice seedlings as a pathogen over a long period of time in Heilongjiang Province or whether the bacteria have been in China for a long time. Pathogenicity of E. cloacae in many hosts represents a risk for agriculture in China. In addition, this data may also provide useful information for implementing effective management strategies in the future.

\section{Literature Cited}

Azegami, K. 2013. Suppressive effect of bacteriophage on bacterial palea browning of rice caused by Pantoea ananatis. J. Gen. Plant Pathol. 79:145-154.

Brady, C., Cleenwerck, I., Venter, S., Coutinho, T., and Vos, P. D. 2013. Taxonomic evaluation of the genus Enterobacter based on multilocus sequence analysis (MLSA): Proposal to reclassify E. nimipressuralis and $E$. amnigenus into Lelliottia gen. nov. as Lelliottia nimipressuralis comb. nov. and Lelliottia amnigena comb. nov., respectively, E. gergoviae and E. pyrinus into Pluralibacter gen. nov. as Pluralibacter gergoviae comb. nov. and Pluralibacter pyrinus comb. nov., respectively, E. cowanii, E. radicincitans, E. oryzae and E. arachidis into Kosakonia gen. nov. as Kosakonia cowanii comb. nov., Kosakonia radicincitans comb. nov., Kosakonia oryzae comb. nov. and Kosakonia arachidis comb. nov., respectively, and E. turicensis, E. helveticus and E. pulveris into Cronobacter as Cronobacter zurichensis nom. nov., Cronobacter helveticus comb. nov. and Cronobacter pulveris comb. nov., respectively, and emended description of the genera Enterobacter and Cronobacter. Syst. Appl. Microbiol. 36:309-319.

Cheng, S. H., Cao, L. Y., Zhuang, J. Y., Chen, S. G., Zhan, X. D., Fan, Y. Y., Zhu, D. F., and Min, S. K. 2007. Super hybrid rice breeding in China: Achievements and prospects. Chin. Bull. Bot. 49:805-810
Cortesi, P., and Pizzatti, C. 2007. Palea browning, a new disease of rice in Italy caused by Pantoea ananatis. J. Plant Pathol. 89:S76.

Doijad, S., Imirzalioglu, C., Yao, Y., Pati, N. B., Falgenhauer, L., Hain, T., Foesel, B. U., Abt, B., Overmann, J., Mirambo, M. M., Mshana, S. E., and Chakraborty, T. 2016. Enterobacter bugandensis sp. nov., isolated from neonatal blood. Int. J. Syst. Evol. Microbiol. 66:968-974.

Eden, P. A., Schmidt, T. M., Blakemore, R. P., and Pace, N. R. 1991. Phylogenetic analysis of Aquaspirillum magnetotacticum using polymerase chain reactionamplified 16S rRNA-specific DNA. Int. J. Syst. Bacteriol. 41:324-325.

Felsenstein, J. 1985. Confidence limits on phylogenies: An approach using the bootstrap. Evolution 39:783-791.

Gavini, F., Lefebvre, B., and Leclerc, H. 1983. Etude taxonomique de souches appartenant ou apparentées au genre Erwinia, groupe Herbicola, et à l'espece Enterobacter agglomerans [Taxonomic study of strains belonging or related to the genus Erwinia, Herbicola group, and to the species Enterobacter agglomerans]. Syst. Appl. Microbiol. 4:218-235.

Gavini, F., Mergaert, J., Beji, A., Mielcarek, C., Izard, D., Kersters, K., and De Ley, J. 1989. Transfer of Enterobacter agglomerans (Beijerinck 1888) Ewing and Fife 1972 to Pantoea gen. nov. as Pantoea agglomerans comb. nov. and Description of Pantoea dispersa sp. nov. Int. J. Syst. Evol. Microbiol. 39: 337-345.

George, M., Potty, V. P., and Jayasankar, N. P. 1976. Association of Enterobacter with coconut root (wilt) disease. Curr. Sci. 45:677-678.

González, A. D., Franco, M. A., Contreras, N., Galindo-Castro, I., Jayaro, Y., and Graterol, E. 2015. First report of Pantoea agglomerans causing rice leaf blight in Venezuela. Plant Dis. 99:552.

Gumma, M. K., Nelson, A., Thenkabail, P. S., and Singh, A. N. 2011. Mapping rice areas of South Asia using MODIS multitemporal data. J. Appl. Remote Sens. 5:053547.

Hasegawa, M., Azegami, K., Yoshida, H., and Otani, H. 2003. Behavior of Erwinia ananas transformed with bioluminescence genes on rice plants. J. Gen. Plant Pathol. 69:267-270.

Hou, Y. M., Zhang, X., Zhang, N. N., Naklumpa, W., Zhao, W. Y., Liang, X. F., Zhang, R., Sun, G. Y., and Gleason, M. L. 2019. Genera Acremonium and Sarocladium cause brown spot on bagged apple fruit in China. Plant Dis. 103:1889-1901.

Keith, R. C., Nishijima, K. A., Keith, L. M., Fitch, M. M., Nishijima, W. T., and Wall, M. M. 2008. Atypical internal yellowing of papaya fruit in Hawaii caused by Enterobacter sakazakii. Plant Dis. 92:487.

Kim, K. Y., Jordan, D., and McDonald, G. A. 1998. Enterobacter agglomerans, phosphate solubilizing bacteria, and microbial activity in soil: Effect of carbon sources. Soil Biol. Biochem. 30:995-1003.

Kim, Y. C., Kim, K. C., and Choi, B. H. 1989. Palea browning disease of rice caused by Erwinia herbicola and ice nucleation activity of the pathogenic bacterium. Korean J. Plant Pathol. 5:72-79.

Kimura, M. 1980. A simple method for estimating evolutionary rates of base substitutions through comparative studies of nucleotide sequences. J. Mol. Evol. 16:111-120.

Kumar, S., Stecher, G., and Tamura, K. 2016. MEGA7: Molecular Evolutionary Genetics Analysis version 7.0 for bigger datasets. Mol. Biol. Evol. 33: $1870-1874$.

Lee, D. H., Kim, J. B., Lim, J., Han, S. W., and Heu, S. 2014. Genetic diversity of Pectobacterium carotovorum subsp. brasiliensis isolated in Korea. Plant Pathol. J. 30:117-124.

Lee, H. B., Hong, J. P., and Kim, S. B. 2010. First report of leaf blight caused by Pantoea agglomerans on rice in Korea. Plant Dis. 94:1372.

Liu, J. X., Cai, Y. N., Jiang, W. Y., Li, Y. G., Zhang, Q. F., and Pan, H. Y. Population structure and genetic diversity of fungi causing rice seedling blight in Northeast China based on microsatellite markers. Plant Dis. In press. doi:10.1094/PDIS-08-19-1620-RE

Liu, S., Lv, M., Gu, Y., and Zhou, J. 2015. First report of bulb disease of onion caused by Klebsiella pneumonia in China. Plant Dis. 99:1853.

Meade, M. J., Nakas, J. P., and Tanenbaum, S. W. 1993. Highly viscous polysaccharide produced by an Enterobacter isolate on a hemicellulose hydrolysate. Biotechnol. Lett. 15:389-392.

Mergaert, J., Verdonck, L., and Kersters, K. 1993. Transfer of Erwinia ananas (synonym, Erwinia uredovora) and Erwinia stewartii to the genus Pantoea emend. as Pantoea ananas (Serrano 1928) comb. nov. and Pantoea stewartii (Smith 1898) comb. nov., respectively, and description of Pantoea stewartii subsp. indologenes subsp. nov. Int. J. Syst. Bacteriol. 43:162-173.

Nishijima, K. A., Alvarez, A. M., Hepperly, P. R., Shintaku, M. H., Keith, L. M., Sato, D. M., Bushe, B. C., Armstrong, J. W., and Zee, F. T. 2004. Association of Enterobacter cloacae with rhizome rot of edible ginger in Hawaii. Plant Dis. 88: $1318-1327$.

Richard, C. 1984. Genus VI. Enterobacter Hormaeche and Edwards 1960, 72; Nom. Cons. Opin. 28, Jud. Comm. 1963, 38. Pages 465-469 in: Bergey's Manual of Systemic Bacteriology, Vol. 1. N. R. Kreig and J. G. Holt, eds. Williams and Wilkins, Baltimore, MD, U.S.A.

Saitou, N., and Nei, M. 1987. The neighbor-joining method: A new method for reconstructing phylogenetic trees. Mol. Biol. Evol. 4:406.

Sanders, W. E., and Sanders, C. C. 1997. Enterobacter spp.: Pathogens poised to flourish at the turn of the century. Clin. Microbiol. Rev. 10:220-241. 
Schaad, N. W. 1988. Pages 311-336 in: Laboratory Guide for Identification of Plant Pathogenic Bacteria. N. W. Schaad, J. B. Jones, and W. Chun, eds. American Phytopathological Society, St. Paul, MN, U.S.A.

Schwartz, H. F., and Otto, K. 2000. First report of a bulb decay of onion by Enterobacter cloacae in Colorado. Plant Dis. 84:808.

Shankar, M., Ponraj, P., Ilakiam, D., Rajendhran, J., and Gunasekaran, P. 2012. Genome sequence of the plant growth-promoting bacterium Enterobacter cloacae GS1. J. Bacteriol. 194:4479.

Stackebrandt, E., and Goodfellow, M., eds. 1991. Nucleic Acid Techniques in Bacterial Systematics. Modern Microbiological Methods. John Wiley \& Sons, New York, NY, U.S.A.

Subrahmanyam, G., Archana, G., Reddy, M. S., Wang, Q., Li, Y., Zhang, L., Du, B., and Yellareddygari, S. K. R. 2011. Plant growth promoting activity of Enterobacter sp. C1D in heavy metal contaminated soils. In: Plant GrowthPromoting Rhizobacteria for Sustainable Agriculture Asian PGPR Conf.

Tabei, H., Azegami, K., and Fukuda, T. 1988. Infection site of rice grain with Erwinia herbicola, the causal agent of bacterial palea browning of rice. Jpn. J. Phytopathol. 54:637-639.

Toh, W. K., Loh, P. C., and Wong, H. L. 2019. First report of leaf blight of rice caused by Pantoea ananatis and Pantoea dispersa in Malaysia. Plant Dis. 103:1764.

Toth, I. K., and Birch, P. R. 2005. Rotting softly and stealthily. Curr. Opin. Plant Biol. 8:424-429.
Wang, G. F., Praphat, K., Xie, G. L., Zhu, B., Li, B., Liu, B., and Zhou, Q. 2008. Bacterial wilt of mulberry (Morus alba) caused by Enterobacter cloacae in China. Plant Dis. 92:483.

Wu, W., Feng, Y., and Zong, Z. 2018. Enterobacter sichuanensis sp. nov., recovered from human urine. Int. J. Syst. Evol. Microbiol. 68:3922-3927.

Wu, W., Wei, L., Feng, Y., Kang, M., and Zong, Z. 2019. Enterobacter huaxiensis sp. nov. and Enterobacter chuandaensis sp. nov., recovered from human blood. Int. J. Syst. Evol. Microbiol. 69:708-714.

Yokozeki, K., Yamanaka, S., Utagawa, T., Takinami, K., Hirose, Y., Tanaka, A., Sonomoto, K., and Fukui, S. 1982. Production of adenine arabinoside by gelentrapped cells of Enterobacter aerogenes in water-organic cosolvent system. Eur. J. Appl. Microbiol. Biotechnol. 14:225-231.

Zaid, A. M., Bonasera, J. M., and Beer, S. V. 2011. First report of Enterobacter bulb decay of onions caused by Enterobacter cloacae in New York. Plant Dis. 95:1581.

Zhang, R. Y., Zhao, S. X., Tan, Z. Q., and Zhu, C. H. 2017. First report of bacterial stem rot disease caused by Paenibacillus polymyxa on Hylocereus undulatus in China. Plant Dis. 101:1031.

Zhao, J. W., Han, L. Y., Yu, M. Y., Cao, P., Li, D. M., Guo, X. W., Liu, Y. Q. Wang, X. J., and Xiang, W. S. 2019. Characterization of Streptomyces sporangiiformans sp. nov., a novel soil actinomycete with antibacterial activity against Ralstonia solanacearum. Microorganisms 7:360. 